\title{
Normalizasyon Yöntemlerinin Çok Ölçütlü Karar Verme Sürecine Etkisi-Moora Yöntemi İncelemesi
}

\author{
The Effects of The Normalization Methods to Multi Criteria Decision Making Process- \\ Moora Method Review
}

Aşkın ÖZDAĞOĞLU'

\begin{abstract}
ÖZET
İşletmeler çok sayıda değerlendirme ölçütünü bir arada gözönüne alarak alternatifler arasında seçim yapmak durumundadırlar. Bu değerlendirme ölçütlerinin ölçüm birimlerinin aynı olması durumu ise gerçek hayatta hemen hemen imkansızdır. Ölçüm birimleri farklı olan ölçütleri birarada incelemek için kullanılan yöntemler çok ölçütlü karar verme yöntemleri adıyla anılmaktadır. Çok ölçütlü karar verme yöntemlerinde ölçüm birimleri farklı olan ölçütleri incelemek için kullanılan çeşitli normalizasyon yöntemleri mevcuttur. Farklı çok ölçütlü karar verme yöntemleri farklı normalizasyon yöntemleri kullanmakta hatta aynı yöntem için literatürde farkı normalizasyon yöntemlerinin kullanıldığı bile görülmektedir. Bu çalışmanın amacı farklı normalizasyon yöntemlerinin alınan kararda bir değişiklik yaratıp yaratmadığını incelemektir. Bu amaçla veri setleri türetilerek Moora çok ölçütlü karar verme yöntemi için farklı normalizasyon yöntemleri uygulanmış ve tercih sırasının değişip değişmediği incelenmiştir.
\end{abstract}

Anahtar Kelimeler: Üretim yönetimi, çok ölçütlü karar verme, normalizasyon, moora

\section{GiRiş}

Işletmeler faaliyetlerini sürdürürken çok sayıda alternatif arasında bir seçim yapma problemiyle sıklıkla karşı karşıya kalmaktadırlar. Üstelik bu alternatifler arasında seçim yapılması sürecinde bir çok farklı faktörü bir arada düşünmek zorundadırlar. Bu faktörlerin ise aynı ölçüm birimine sahip olması gerçek hayatta hemen hemen hiç gerçekleşmemektedir. Hatta servis kalitesi, tedarikçinin güvenilir olması gibi bazı faktörlerde bir ölçüm cihazı ile ölçüm yapmak bile mümkün olmamaktadır. Ancak sağ ıklı bir karar verme sürecinin gerçekleşebilmesi için nitel faktörlerin ölçülememesi nedeniyle değerlendirme sürecinden çıkarılması gibi bir durum da sözkonusu olamayacaktır. Herhangi bir ölçüm cihazı vasıtasıyla ölçüm yapılsa bile bunların birimleri aynı olmayacağından bu veriler de doğrudan kullanılamayacaktır. Çok ölçütlü karar verme yön-

\begin{abstract}
Companies have to make a choice among alternatives by taking into consideration many different evaluation criteria together. In real world, same measurement units of the evaluation criteria are impossible. The methods used for analysing the evaluation criteria which have got different measurement units are called multi criteria decision making methods. There have been different normalization methods used for analysing the evaluation criteria which have got different measurement units in the multi criteria decision making methods. The different multi criteria decision making methods have used different normalization methods. Moreover, the different normalization methods can be used in the same multi criteria decision making method. The purpose of this study is to analyse the effects of the different normalization methods in the decision. For this purpose, the data sets have been derived. Then, the preference rankings have been analysed for Moora multi criteria decision making method by applying different normalization methods for the data sets.
\end{abstract}

Keywords: Production management, multi criteria decision making, normalization, moora

temleri bu tür sorunların üstesinden gelebilmek için normalizasyon yöntemlerinden yararlanmaktadır. $\mathrm{Bu}$ normalizasyon yöntemleri mevcut bulunan değerleri birimi olmayan değerlere dönüştürerek birlikte incelenmelerine olanak sağlamaktadır. Bu noktada farklı çok ölçütlü karar verme yöntemlerinin değerlendirme sürecinde yararlandıkları belirgin bir normalizasyon yöntemi mevcuttur. Örnek vermek gerekirse Topsis yöntemi çoğunlukla vektörel normalizasyondan yararlanmakta ve ideal çözüme uzaklığı bulmaktadır. Doğrusal normalizasyon yöntemininin tercih edildiği çok ölçütlü karar verme yöntemleri de bulunmaktadır. Fakat doğrusal normalizasyon için de dört farklı yöntem mevcuttur. Ayrıca literatür incelendiğinde aynı çok ölçütlü karar verme yönteminin uygulandığı farklı makalelerde farklı normalizasyon yöntemleri seçilmekte ve bir standarta sahip olmamaktadır. Örnek vermek gerekirse Moora yöntemi için doğrusal 
normalizasyon ve vektörel normalizasyon yöntemi kullanılan çalışmalara rastlamak mümkündür. Bu noktada bir soru ortaya çıkmaktadır. Acaba normalizasyon yöntemi verilen kararı etkiler mi? Bu çalışmada farklı normalizasyon yöntemleri seçilmiş olan bir çok ölçütlü karar verme yöntemi için farklı veri setlerine uygulanacak ve alternatiflerin tercih sırasında belirgin değişiklikler olup olmadığı korelasyon analizi ile incelenecektir. Verilerin gerçek işletme durumlarını daha iyi yansıtabilmesini de sağlamak amacıyla bu değerlendirme ölçütlerinden sonuncusu için zaman ve maliyet gibi değerin en küçük olmasının en iyi durumu gösterdiği düşünülerek işlemler gerçekleştirilecektir.

\section{NORMALIZASYON YÖNTEMLERI}

Normalizasyon yöntemleri üç ana başlıkta toplanabilmektedir.

- Vektör Normalizasyonu

- Doğrusal Normalizasyon

- Monoton Olmayan Normalizasyon

Bu normalizasyon yöntemlerinden doğrusal normalizasyon da farklı şekillerde uygulanabilmektedir. Yöntemlerin uygulanışına ilişkin formüller sunulmadan önce değişkenlerin tanıtılması yerinde olacaktır. Bir çok ölçütlü karar verme probleminde normalizasyon işlemine tabi olacak değişkenler aşağıdaki gibi gösterilsin (Shih vd., 2007: 805).

$A_{i}$ i. alternatif $i=1,2, \ldots, m$

$C_{j}$ j. değerlendirme ölçütü $j=1,2, \ldots, n$

$x_{i j}=j$. değerlendirme ölçütü açısından i. alternatifin değeri

Bu değişkenlere göre oluşan karar matrisi Eşitlik 1 'de gösterilmiştir.

$$
D=A_{3}\left[\begin{array}{ccccc}
A_{1} \\
A_{2} \\
\cdot \\
A_{m}
\end{array}\left[\begin{array}{ccccc}
x_{11} & x_{12} & x_{13} & \cdot & x_{1 n} \\
x_{21} & x_{22} & x_{23} & \cdot & x_{2 n} \\
x_{31} & x_{32} & x_{33} & \cdot & x_{3 n} \\
\cdot & \cdot & \cdot & \cdot & \cdot \\
x_{m 1} & x_{m 2} & x_{m 3} & \cdot & x_{m n}
\end{array}\right]\right.
$$

Eşitlik 1.

Normalizasyon yöntemlerinin bu değişkenler doğrultusunda uygulanması Eşitlik 2-10 aralığında sunulmuştur.

\section{Vektör normalizasyonu}

$$
r_{i j}=\frac{x_{i j}}{\sqrt{\sum_{i=1}^{m} x_{i j}^{2}}}, i=1,2, \ldots, m ; j=1,2, \ldots, n . \quad \text { Eşitlik } 2 .
$$

Doğrusal normalizasyon (1)

$$
r_{i j}=\frac{x_{i j}}{x_{j}^{*}} i=1,2, \ldots, m ; j=1,2, \ldots, n ; x_{j}^{*}=\max _{i}\left(x_{i j}\right)
$$

(ölçüt için en iyi durum maksimizasyon ise). Eşitlik 3.

$$
r_{i j}=\frac{x_{j}^{-}}{x_{i j}} i=1,2, \ldots, m ; j=1,2, \ldots, n ; x_{j}^{-}=\min _{i}\left(x_{i j}\right)
$$

(ölçüt için en iyi durum minimizasyon ise). Essitlik 4.

Doğrusal normalizasyon (2)

$$
r_{i j}=\frac{x_{i j}}{x_{j}^{*}} i=1,2, \ldots, m ; j=1,2, \ldots, n ; x_{j}^{*}=\max _{i}\left(x_{i j}\right)
$$

(ölçüt için en iyi durum maksimizasyon ise).Eşitlik 5.

$$
r_{i j}=1-\frac{x_{i j}}{x_{j}^{*}} i=1,2, \ldots, m ; j=1,2, \ldots, n ; x_{j}^{*}=\max _{i}\left(x_{i j}\right)
$$

(ölçüt için en iyi durum minimizasyon ise). Eşitlik 6.

\section{Doğrusal normalizasyon (3)}

$$
r_{i j}=\frac{x_{i j}-x_{j}^{-}}{x_{j}^{*}-x_{j}^{-}} i=1,2, \ldots, m ; j=1,2, \ldots, n ; x_{j}^{*}=\max _{i}\left(x_{i j}\right),
$$

$\mathrm{x}_{\mathrm{j}}^{-}=\min _{\mathrm{i}}\left(\mathrm{x}_{\mathrm{ij}}\right)$ (ölçüt için en iyi durum maksimizasyon

ise).

Eşitlik 7.

$$
r_{i j}=\frac{x_{j}^{*}-x_{i j}}{x_{j}^{*}-x_{j}^{-}} i=1,2, \ldots, m ; j=1,2, \ldots, n ; x_{j}^{*}=\max _{i}\left(x_{i j}\right)
$$
, $\mathrm{x}_{\mathrm{j}}^{-}=\min _{\mathrm{i}}\left(\mathrm{x}_{\mathrm{ij}}\right)$ (ölçüt için en iyi durum minimizasyon ise).

Eşitlik 8.

Doğrusal normalizasyon (4)

$$
r_{i j}=\frac{x_{i j}}{\sum_{i=1}^{m} x_{i j}}, i=1,2, \ldots, m ; j=1,2, \ldots, n . \quad \text { Eşitlik } 9 .
$$

Monoton olmayan normalizasyon

$\mathrm{x}_{\mathrm{j}}^{0}$ : j ölçütüne ilişkin en uygun değer

$o_{j}$ : j ölçütüne ilişkin değerlerin standart sapması

$$
e^{\left(-z^{2} / 2\right)}, \mathrm{z}=\frac{\mathrm{x}_{\mathrm{ij}}-\mathrm{x}_{\mathrm{j}}^{0}}{\mathrm{o}_{\mathrm{j}}}
$$

Eşitlik 10.

\section{LITERATÜR INCELEMESI}

Literatür incelendiğinde çok ölçütlü karar verme yöntemi kullanılarak alternatifler arasında seçim yapılan bir çok çalışma ile karşılaşılmaktadır. Çalışmada kullanılan çok ölçütlü karar verme yöntemi ile normalizasyon yöntemlerine ilişkin kısa bir liste Tablo 1 'de verilmiştir. 
Tablo 1: Çalışmada Kullanılan Çok Ölçütlü Karar Verme ve Normalizasyon Yöntemleri

\begin{tabular}{|c|c|c|}
\hline $\begin{array}{l}\text { Kullanılan Çok } \\
\text { Ölçütlü Karar } \\
\text { Verme Yöntemi }\end{array}$ & $\begin{array}{c}\text { Kullanılan } \\
\text { Normalizasyon } \\
\text { Yöntemi }\end{array}$ & Çalışma \\
\hline Topsis & $\begin{array}{l}\text { Vektör } \\
\text { Normalizasyonu }\end{array}$ & $\begin{array}{l}\text { Peng vd., 2011; } \\
\text { Huang ve Huang, } \\
\text { 2012; Sun vd., 2011; } \\
\text { Sadeghzadeh ve } \\
\text { Salehi, 2011; Aalami } \\
\text { vd., 2010; Ayala, } \\
\text { 2012; Kiran vd., 2011; } \\
\text { Lozano-Minguez vd., } \\
2011\end{array}$ \\
\hline - & $\begin{array}{l}\text { Doğrusal } \\
\text { Normalizasyon (1) }\end{array}$ & - \\
\hline Topsis & $\begin{array}{l}\text { Doğrusal } \\
\text { Normalizasyon (2) }\end{array}$ & Ouattara vd., 2012 \\
\hline Exprom2 & $\begin{array}{l}\text { Doğrusal } \\
\text { Normalizasyon (3) }\end{array}$ & $\begin{array}{l}\text { Chatterjee ve } \\
\text { Chakraborty, } 2012\end{array}$ \\
\hline Copras & $\begin{array}{l}\text { Doğrusal } \\
\text { Normalizasyon (4) }\end{array}$ & $\begin{array}{l}\text { Das vd., 2012; } \\
\text { Chatterjee vd., 2011; } \\
\text { Kaklauskas vd., 2010; } \\
\text { Kaklauskas vd., } 2007\end{array}$ \\
\hline - & $\begin{array}{l}\text { Monoton Olmayan } \\
\text { Normalizasyon }\end{array}$ & - \\
\hline Topsis & $\begin{array}{l}\text { Doğrusal } \\
\text { Normalizasyon (3) }\end{array}$ & $\begin{array}{l}\text { Mela vd., 2012; Dai ve } \\
\text { Wang, } 2011\end{array}$ \\
\hline Moora & $\begin{array}{l}\text { Doğrusal } \\
\text { Normalizasyon (4) }\end{array}$ & $\begin{array}{l}\text { Karande ve } \\
\text { Chakraborty, } 2012\end{array}$ \\
\hline Multimoora & $\begin{array}{l}\text { Vektör } \\
\text { Normalizasyonu }\end{array}$ & $\begin{array}{l}\text { Balezentis vd., 2012; } \\
\text { Streimikiene vd., } 2012\end{array}$ \\
\hline Moora & $\begin{array}{l}\text { Vektör } \\
\text { Normalizasyonu }\end{array}$ & Chakraborty, 2011 \\
\hline
\end{tabular}

Electre ve Promethee gibi bazı çok ölçütlü karar verme yöntemlerinde ikili karşılaştırmalar yapıldığından ayrıca normalizasyon yöntemi uygulanmasına gerek kalmadığından listede bu çok ölçütlü karar verme yöntemlerine ilişkin örnekler mevcut değildir. Wsm ve Wpm yöntemleri de her bir değerlendirme ölçütünün aynı ölçeğe sahip olduğu durumlarda kulllanılabildiğinden bu listede bir örneği bulunmamaktadır. Tablo 1'deki örnek çalışmalardan da görüleceği üzere, farklı çok ölçütlü karar verme yöntemlerinde farklı normalizasyon yöntemleri kullanılmaktadır. Üstelik Topsis ve Moora gibi çok ölçütlü karar verme yöntemleri için standart bir normalizasyon yönteminin de olmadığı görülmektedir. Copras yöntemi için Doğrusal normalizasyon (4) şeklinde standart bir tercih yapıldığı görülürken, Topsis ve Moora yöntemlerinde hem doğrusal normalizasyon hem de vektör normalizasyonu uygulanabilmektedir. İzleyen kısımda farklı normalizasyon yöntemleri kullanılmasının seçim kararını nasıl etkileyeceğini görmek üzere literatür incelemesinde de belirtildiği gibi üzerinde mutabakat sağlanmayan çok ölçütlü karar verme yöntemle- rinden Moora yöntemi ile denemeler yapılacağından dolayı Moora yönteminin işleyişi gösterilecektir.

\section{MOORA YÖNTEMI}

MOORA (Multi-Objective Optimization on the basis of Ratio Analysis) yöntemi (çok ölçütlü ya da çok nitelikli olarak ta ifade edilebilmektedir.) iki veya daha fazla çakışan niteliği veya amacı belirli kısıtlar altında eş zamanlı olarak optimize etme sürecidir. MOORA yöntemi çeşitli nitelikler ya da amaçlara ilişkin farklı alternatiflerin performansını gösteren Eşitlik 11'deki karar matrisi ile başlar (Brauers ve Zavadskas, 2009; Chakraborty, 2011: 1156-1157).

$$
X=\left[\begin{array}{cccc}
\mathrm{x}_{11} & \mathrm{x}_{12} & \ldots & \mathrm{x}_{1 \mathrm{n}} \\
\mathrm{x}_{21} & \mathrm{x}_{22} & \ldots & \mathrm{x}_{2 \mathrm{n}} \\
\ldots & \ldots & \ldots & \ldots \\
\mathrm{x}_{\mathrm{m} 1} & \mathrm{x}_{\mathrm{m} 2} & \ldots & \mathrm{x}_{\mathrm{mn}}
\end{array}\right]
$$

Eşitlik 11.

Bu karar matrisinde,

$\mathrm{i}=$ alternatif

$j=$ nitelik yada ölçüt

$\mathrm{m}=$ toplam alternatif sayısı

$\mathrm{n}=$ toplam nitelik yada ölçüt sayısı

$x_{i j}=i$. Alternatifin $j$. ölçüt açısından performans ölçüm değeri olarak ifade edilmektedir. Daha sonra, normalizasyon işlemi gerçekleştirilir. Normalizasyon için kullanılan yöntemler Eşitlik 2'de gösterilen vektör normalizasyonu ve Eşitlik 9'da sunulan doğrusal normalizasyon (4)'tür. Bu işlem $x_{i j}$ ile gösterilen $i$. Alternatifin $j$. ölçüt açısından performans ölçüm değerini verir. Buradaki $x_{i j}$ değeri $j$ Ölçüt yada nitelik açısından $i$. Alternatifin normalize edilmiş performansını temsil eden $[0,1]$ aralığında yer alan birimi bulunmayan bir sayıdır. Çok amaçı optimizasyon için, bu normalize edilmiş performans değerleri (faydalı nitelikler için) maksimizasyon durumunda eklenip, (faydasız nitelikler için) minimizasyon durumunda çıkarılarak her bir alternatif için tek bir değer bulunur. Bu durumda optimizasyon problemi 12 numaralı denklemdeki gibi oluşur.

$$
\mathrm{y}_{\mathrm{i}}=\sum_{\mathrm{j}=1}^{\mathrm{g}} \mathbf{x}_{\mathrm{ij}}^{*}-\sum_{\mathrm{j}=\mathrm{g}+1}^{\mathrm{n}} \mathbf{x}_{\mathrm{ij}}^{*}
$$

Bu eşitlikte,

n= enbüyüklenecek nitelik ya da ölçüt sayısı

n-g = enküçüklenecek nitelik ya da ölçüt sayısı

$y_{i}=$ tüm nitelik ya da ölçütler açısından i. Alternatife ilişkin normalize edilmiş değer. 
Çoğu durumda, belirli nitelik ya da ölçütlerin diğerlerine göre daha önemli olduğu görülmektedir. Bir nitelik ya da ölçüte daha fazla önem vermek için ilgili oran o nitelik ya da ölçüte ait ağılık değeri (önem katsayısı) ile çarpılabilir. Niteliklerin ağılıkları göz önüne alındığında 12 numaralı denklem, 13 numaralı denklem şekline dönüşmektedir.

$$
y_{i}=\sum_{j=1}^{g} w_{j} x_{i j}^{*}-\sum_{j=g+1}^{n} w_{j} x_{i j}^{*}(j=1,2, \ldots, n)
$$

Eşitlik 13.

$\mathrm{w}_{\mathrm{j}}=\mathrm{j}$. Nitelik ya da ölçütün ağırlık (önem) katsayısı

$y_{i}$ değeri karar matrisindeki enbüyüklerin (faydalı nitelik ya da ölçütler) ve enküçüklerin (faydasız nitelik ya da ölçütler) toplamlarına bağlı olarak pozitif veya negatif değer alabilir. $y_{i}$ değerlerinin sıralaması nihai öncelikleri gösterir. En iyi alternatif en yüksek $y_{i}$ değerine sahip olan iken, en kötü alternatif en düşük $y_{i}$ değerine sahip olan alternatiftir.

\section{UYGULAMA}

Bu çalışmada uygulama kapsamında on alternatif ve beş farklı değerlendirme ölçütüne göre on farklı veri seti oluşturulmuş ve Moora yöntemi için tüm normalizasyon yöntemleri denenerek sıralama sonuçları karşılaştırılmıştır. Örnek veri seti içinde değerlendirme ölçütü 5 için mümkün olan en küçük değerin en iyi durumu temsil ettiği düşünülerek hesaplamalar gerçekleştirilmiştir. Veri setlerinin oluşturulmasında MS Excel programından yararlanılmıştır. Her bir değerlendirme ölçütü açısından farklı değer aralıkları ile incelemeler gerçekleştirilmiştir. Değerlendirme ölçütlerine göre on farklı alternatif ve on farklı veri seti yaratılmasında kullanılan fonksiyonlar Tablo 2'de gösterilmiştir.

Tablo 2: Değer Oluşturmada Kullanılan Fonksiyonlar

\begin{tabular}{|l|l|}
\hline Değerlendirme Ölçütü & Excel fonksiyonu \\
\hline Değerlendirme Ölçütü 1 & $=$ RANDBETWEEN(500;1000) \\
\hline Değerlendirme Ölçütü 2 & $=$ RANDBETWEEN(0;100) \\
\hline Değerlendirme Ölçütü 3 & $=$ RANDBETWEEN(50;200) \\
\hline Değerlendirme Ölçütü 4 & $=$ RANDBETWEEN(100;170) \\
\hline Değerlendirme Ölçütü 5 & $=$ RANDBETWEEN(540;850) \\
\hline
\end{tabular}

Bu fonksiyonların kullanımı neticesinde elde edilen veri setleri Tablo 3'te verilmiştir. Verilerin gerçek işletme durumlarını daha iyi yansıtabilmesini de sağlamak amacıyla bu değerlendirme ölçütlerinden sonuncusu için zaman ve maliyet gibi değerin en küçük olmasının en iyi durumu gösterdiği düşünülerek işlemler gerçekleştirilmiştir. Bu sebeple Tablo 3 içerisinde ölçüt numaralarının belirtildiği hücrelerin altında "maksimum ifadesi yazılı iken son ölçüt için "minimum" ifadesi yazılıdır.

Tablo 3: Veri Setleri

\begin{tabular}{|c|c|c|c|c|c|c|}
\hline & & $\begin{array}{c}\text { Ölçüt } \\
1\end{array}$ & $\begin{array}{l}\text { Ölçüt } \\
2\end{array}$ & $\begin{array}{c}\text { Ölçüt } \\
3\end{array}$ & $\begin{array}{c}\text { Ölçüt } \\
4\end{array}$ & $\begin{array}{l}\text { Ölçüt } \\
5\end{array}$ \\
\hline & & $\begin{array}{c}\text { maksi- } \\
\text { mum }\end{array}$ & $\begin{array}{c}\text { maksi- } \\
\text { mum }\end{array}$ & $\begin{array}{c}\text { maksi- } \\
\text { mum }\end{array}$ & $\begin{array}{c}\text { maksi- } \\
\text { mum }\end{array}$ & $\begin{array}{l}\text { mini- } \\
\text { mum }\end{array}$ \\
\hline \multirow{10}{*}{ 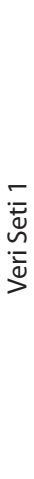 } & Alternatif 1 & 733 & 46 & 188 & 125 & 640 \\
\hline & Alternatif 2 & 995 & 50 & 130 & 123 & 588 \\
\hline & Alternatif 3 & 673 & 31 & 100 & 118 & 776 \\
\hline & Alternatif 4 & 532 & 81 & 197 & 135 & 564 \\
\hline & Alternatif 5 & 869 & 89 & 167 & 116 & 833 \\
\hline & Alternatif 6 & 946 & 16 & 154 & 163 & 661 \\
\hline & Alternatif 7 & 781 & 24 & 136 & 146 & 828 \\
\hline & Alternatif 8 & 825 & 89 & 148 & 118 & 808 \\
\hline & Alternatif 9 & 878 & 27 & 77 & 106 & 603 \\
\hline & Alternatif 10 & 594 & 87 & 140 & 164 & 561 \\
\hline \multirow{10}{*}{ 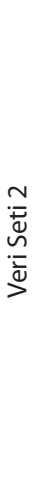 } & Alternatif 1 & 872 & 97 & 65 & 142 & 848 \\
\hline & Alternatif 2 & 685 & 5 & 109 & 161 & 778 \\
\hline & Alternatif 3 & 679 & 74 & 50 & 147 & 590 \\
\hline & Alternatif 4 & 551 & 33 & 108 & 130 & 847 \\
\hline & Alternatif 5 & 901 & 55 & 109 & 106 & 765 \\
\hline & Alternatif 6 & 744 & 54 & 169 & 161 & 594 \\
\hline & Alternatif 7 & 653 & 68 & 171 & 151 & 655 \\
\hline & Alternatif 8 & 747 & 85 & 143 & 149 & 606 \\
\hline & Alternatif 9 & 540 & 57 & 123 & 103 & 651 \\
\hline & Alternatif 10 & 577 & 31 & 189 & 118 & 626 \\
\hline \multirow{10}{*}{ 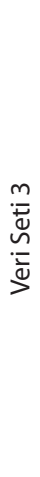 } & Alternatif 1 & 616 & 12 & 123 & 143 & 580 \\
\hline & Alternatif 2 & 652 & 83 & 156 & 140 & 830 \\
\hline & Alternatif 3 & 672 & 36 & 97 & 163 & 653 \\
\hline & Alternatif 4 & 709 & 74 & 93 & 107 & 845 \\
\hline & Alternatif 5 & 504 & 38 & 90 & 169 & 546 \\
\hline & Alternatif 6 & 702 & 7 & 123 & 135 & 674 \\
\hline & Alternatif 7 & 586 & 97 & 157 & 107 & 587 \\
\hline & Alternatif 8 & 970 & 82 & 174 & 155 & 715 \\
\hline & Alternatif 9 & 879 & 36 & 114 & 106 & 552 \\
\hline & Alternatif 10 & 736 & 38 & 167 & 123 & 736 \\
\hline \multirow{10}{*}{ 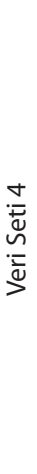 } & Alternatif 1 & 843 & 60 & 52 & 137 & 637 \\
\hline & Alternatif 2 & 646 & 42 & 172 & 148 & 630 \\
\hline & Alternatif 3 & 926 & 87 & 177 & 121 & 762 \\
\hline & Alternatif 4 & 646 & 97 & 84 & 104 & 778 \\
\hline & Alternatif 5 & 519 & 47 & 105 & 115 & 848 \\
\hline & Alternatif 6 & 928 & 10 & 97 & 161 & 752 \\
\hline & Alternatif 7 & 577 & 84 & 139 & 132 & 706 \\
\hline & Alternatif 8 & 722 & 20 & 63 & 141 & 669 \\
\hline & Alternatif 9 & 773 & 42 & 157 & 105 & 713 \\
\hline & Alternatif 10 & 944 & 45 & 198 & 119 & 784 \\
\hline
\end{tabular}




\begin{tabular}{|c|c|c|c|c|c|c|}
\hline & & $\begin{array}{c}\text { Ölçüt } \\
1\end{array}$ & $\begin{array}{c}\text { Ölçüt } \\
2\end{array}$ & $\begin{array}{c}\text { Ölçüt } \\
3\end{array}$ & $\begin{array}{c}\text { Ölçüt } \\
4\end{array}$ & $\begin{array}{c}\text { Ölçüut } \\
5\end{array}$ \\
\hline & & $\begin{array}{c}\text { maksi- } \\
\text { mum }\end{array}$ & $\begin{array}{c}\text { maksi- } \\
\text { mum }\end{array}$ & $\begin{array}{c}\text { maksi- } \\
\text { mum }\end{array}$ & $\begin{array}{l}\text { maksi- } \\
\text { mum }\end{array}$ & $\begin{array}{l}\text { mini- } \\
\text { mum }\end{array}$ \\
\hline \multirow{10}{*}{ 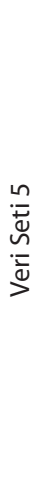 } & Alternatif 1 & 721 & 25 & 55 & 114 & 779 \\
\hline & Alternatif 2 & 911 & 59 & 137 & 122 & 574 \\
\hline & Alternatif 3 & 793 & 52 & 199 & 166 & 834 \\
\hline & Alternatif 4 & 600 & 35 & 167 & 152 & 580 \\
\hline & Alternatif 5 & 786 & 58 & 56 & 165 & 567 \\
\hline & Alternatif 6 & 937 & 72 & 103 & 125 & 727 \\
\hline & Alternatif 7 & 639 & 53 & 78 & 138 & 597 \\
\hline & Alternatif 8 & 968 & 91 & 108 & 119 & 746 \\
\hline & Alternatif 9 & 936 & 41 & 167 & 100 & 597 \\
\hline & Alternatif 10 & 984 & 95 & 73 & 101 & 832 \\
\hline \multirow{10}{*}{ 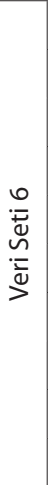 } & Alternatif 1 & 854 & 84 & 87 & 134 & 601 \\
\hline & Alternatif 2 & 615 & 100 & 142 & 164 & 544 \\
\hline & Alternatif 3 & 562 & 72 & 193 & 170 & 762 \\
\hline & Alternatif 4 & 984 & 17 & 193 & 121 & 744 \\
\hline & Alternatif 5 & 889 & 88 & 107 & 164 & 788 \\
\hline & Alternatif 6 & 566 & 76 & 150 & 108 & 764 \\
\hline & Alternatif 7 & 945 & 43 & 149 & 121 & 740 \\
\hline & Alternatif 8 & 857 & 1 & 162 & 135 & 810 \\
\hline & Alternatif 9 & 762 & 49 & 174 & 107 & 797 \\
\hline & Alternatif 10 & 622 & 26 & 57 & 167 & 790 \\
\hline \multirow{10}{*}{ 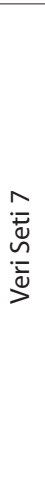 } & Alternatif 1 & 650 & 46 & 159 & 115 & 560 \\
\hline & Alternatif 2 & 900 & 38 & 145 & 140 & 705 \\
\hline & Alternatif 3 & 870 & 34 & 153 & 164 & 742 \\
\hline & Alternatif 4 & 685 & 47 & 91 & 167 & 693 \\
\hline & Alternatif 5 & 520 & 87 & 58 & 160 & 771 \\
\hline & Alternatif 6 & 909 & 97 & 168 & 134 & 569 \\
\hline & Alternatif 7 & 546 & 77 & 71 & 120 & 597 \\
\hline & Alternatif 8 & 535 & 89 & 100 & 134 & 691 \\
\hline & Alternatif 9 & 770 & 47 & 194 & 105 & 548 \\
\hline & Alternatif 10 & 899 & 58 & 73 & 139 & 817 \\
\hline \multirow{10}{*}{ 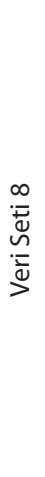 } & Alternatif 1 & 502 & 60 & 153 & 159 & 785 \\
\hline & Alternatif 2 & 913 & 65 & 105 & 136 & 658 \\
\hline & Alternatif 3 & 703 & 58 & 139 & 159 & 547 \\
\hline & Alternatif 4 & 518 & 81 & 170 & 146 & 641 \\
\hline & Alternatif 5 & 941 & 78 & 155 & 150 & 616 \\
\hline & Alternatif 6 & 631 & 27 & 198 & 149 & 824 \\
\hline & Alternatif 7 & 519 & 71 & 175 & 158 & 712 \\
\hline & Alternatif 8 & 563 & 83 & 166 & 127 & 793 \\
\hline & Alternatif 9 & 957 & 18 & 127 & 167 & 659 \\
\hline & Alternatif 10 & 753 & 86 & 81 & 144 & 696 \\
\hline
\end{tabular}

\begin{tabular}{|c|c|c|c|c|c|c|}
\hline & & $\begin{array}{c}\text { Ölçüt } \\
1\end{array}$ & $\begin{array}{c}\text { Ölçüt } \\
2\end{array}$ & $\begin{array}{c}\text { Ölçüt } \\
3\end{array}$ & $\begin{array}{c}\text { Ölçüt } \\
4\end{array}$ & $\begin{array}{c}\text { Ölçüt } \\
5\end{array}$ \\
\hline & & $\begin{array}{c}\text { maksi- } \\
\text { mum }\end{array}$ & $\begin{array}{l}\text { maksi- } \\
\text { mum }\end{array}$ & $\begin{array}{c}\text { maksi- } \\
\text { mum }\end{array}$ & $\begin{array}{c}\text { maksi- } \\
\text { mum }\end{array}$ & $\begin{array}{l}\text { mini- } \\
\text { mum }\end{array}$ \\
\hline \multirow{10}{*}{ 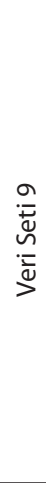 } & Alternatif 1 & 649 & 54 & 128 & 137 & 733 \\
\hline & Alternatif 2 & 743 & 5 & 113 & 105 & 835 \\
\hline & Alternatif 3 & 887 & 74 & 84 & 138 & 551 \\
\hline & Alternatif 4 & 853 & 2 & 54 & 140 & 727 \\
\hline & Alternatif 5 & 760 & 50 & 126 & 142 & 573 \\
\hline & Alternatif 6 & 698 & 86 & 146 & 162 & 687 \\
\hline & Alternatif 7 & 989 & 22 & 200 & 121 & 664 \\
\hline & Alternatif 8 & 665 & 69 & 117 & 120 & 666 \\
\hline & Alternatif 9 & 666 & 57 & 137 & 149 & 769 \\
\hline & Alternatif 10 & 730 & 100 & 177 & 142 & 725 \\
\hline \multirow{10}{*}{ 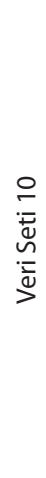 } & Alternatif 1 & 762 & 89 & 171 & 128 & 807 \\
\hline & Alternatif 2 & 553 & 2 & 192 & 101 & 595 \\
\hline & Alternatif 3 & 758 & 43 & 138 & 145 & 731 \\
\hline & Alternatif 4 & 970 & 48 & 174 & 138 & 784 \\
\hline & Alternatif 5 & 625 & 71 & 171 & 147 & 602 \\
\hline & Alternatif 6 & 561 & 28 & 175 & 139 & 659 \\
\hline & Alternatif 7 & 567 & 78 & 81 & 103 & 746 \\
\hline & Alternatif 8 & 858 & 35 & 86 & 165 & 705 \\
\hline & Alternatif 9 & 656 & 76 & 62 & 102 & 639 \\
\hline & Alternatif 10 & 932 & 55 & 71 & 118 & 609 \\
\hline
\end{tabular}

$\mathrm{Bu}$ veri setlerine tüm normalizasyon yöntemleri denenerek Moora yöntemi ile $y_{i}$ değerleri hesaplanmıştır. Elde edilen $y_{i}$ değerleri Tablo 4'te sunulmuştur. Tablo 4'ün ilk satırında yer alan $y_{i}$ değerlerinin Tablo 3'teki veriler kullanılarak hesaplanması aşağıda gösterilmiştir.

Vektör normalizasyonuna göre ilk olarak 2 numaralı denklem kullanılmıştır.

$$
\sqrt{\frac{733}{733^{2}+995^{2}+673^{2}+\ldots+594^{2}}}=0,291395
$$

Ardından 13 numaralı denklemden yararlanılır. Bu denklemde tüm ölçütlerin eşit öneme sahip olduğu düşünülerek 0,2 değeri kullanılmıştır.

$(0,2) *(0,291395)+(0,2) *(0,238788)+(0,2) *$ $(0,402111)+(0,2) *(0,297703)-(0,2) *(0,291415)$ $=0,187716$

Son ölçüt için değerin en küçük olması en iyi durumu gösterdiğinden dolayı ilk dört değer toplanmış iken sonuncusu çıkarılmıştır.

Doğrusal normalizasyon (1) yöntemine göre ilk dört ölçüt için 3 numaralı denklem, son ölçüt için ise 4 numaralı denklemden yararlanılır. 


$$
\frac{733}{\max \{733 ; 995 ; 673 ; \ldots ; 594\}}=0,736683
$$

Ardından 13 numaralı denklemden yararlanılır.

$(0,2) *(0,736683)+(0,2) *(0,516854)+(0,2) *(0,9543$ $15)+(0,2) *(0,762195)+(0,2) *(0,876563)=0,769322$

Doğrusal normalizasyon (1) yöntemi ölçüt için en iyi durumun maksimizasyon veya minimizasyon olmasına göre farklı denklemlerden yararlandığından dolayı son ölçüt için çıkarma işlemine gerek kalmamaktadır. Ölçüt 5 için yapılan normalizasyon işlemindeki farklılık aşağıda gösterilmiştir.

$$
\frac{\min \{640 ; 588 ; 776 ; \ldots ; 561\}}{640}=0,876563
$$

Doğrusal normalizasyon (2) yöntemine göre ilk dört ölçüt için 5 numaralı denklem, son ölçüt için ise 6 numaralı denklemden yararlanılır.

$$
\frac{733}{\max \{733 ; 995 ; 673 ; \ldots ; 594\}}=0,736683
$$

Ardından 13 numaralı denklemden yararlanılır.

$(0,2) *(0,736683)+(0,2) *(0,516854)+(0,2) *(0,9543$ $15)+(0,2) *(0,762195)+(0,2) *(0,231693)=0,640348$

Doğrusal normalizasyon (2) yöntemi ölçüt için en iyi durumun maksimizasyon veya minimizasyon olmasına göre farklı denklemlerden yararlandığından dolayı son ölçüt için çıkarma işlemine gerek kalmamaktadır. Ölçüt 5 için yapılan normalizasyon işlemindeki farklılık aşağıda gösterilmiştir.

$$
1-\frac{640}{\max \{640 ; 588 ; 776 ; \ldots ; 561\}}=0,231693
$$

Doğrusal normalizasyon (3) yöntemine göre ilk dört ölçüt için 7 numaralı denklem, son ölçüt için ise 8 numaralı denklemden yararlanılır.

$\frac{733-\min \{733 ; 995 ; 673 ; \ldots ; 594\}}{\max \{733 ; 995 ; 673 ; \ldots ; 594\}-\min \{733 ; 995 ; 673 ; \ldots ; 594\}}=0,434125$

Ardından 13 numaralı denklemden yararlanılır.

$(0,2) *(0,434125)+(0,2) *(0,410959)+(0,2) *(0,9250$ $00)+(0,2) *(0,327586)+(0,2) *(0,709559)=0,561446$

Doğrusal normalizasyon (3) yöntemi ölçüt için en iyi durumun maksimizasyon veya minimizasyon olmasına göre farklı denklemlerden yararlandığından dolayı son ölçüt için çıkarma işlemine gerek kalma- maktadır. Ölçüt 5 için yapılan normalizasyon işlemindeki farklılık aşağıda gösterilmiştir.

$$
\frac{\max \{640 ; 588 ; 776 ; \ldots ; 561\}-640}{\max \{640 ; 588 ; 776 ; \ldots ; 561\}-\min \{640 ; 588 ; 776 ; \ldots ; 561\}}=0,709559
$$

Doğrusal normalizasyon (4) yöntemine göre tüm ölçütler için tek bir denklem mevcuttur. Hesaplamalar için 9 numaralı denklemden yararlanılır.

$$
\frac{733}{733+995+673+\ldots+594}=0,093662
$$

Ardından 13 numaralı denklemden yararlanılır.

$(0,2) *(0,093662)+(0,2) *(0,085185)+(0,2) *$ $(0,130828)+(0,2) *(0,095129)-(0,2) *(0,093267)=$ 0,062308

Ölçüt için en iyi durumun maksimizasyon veya minimizasyon olmasına farketmeksizin tek bir denklemden yararlanıldığından dolayı son ölçüt için çıkarma işlemi yapılması gerekmektedir.

Monoton olmayan normalizasyon yöntemine göre 10 numaralı denklemden yararlanılır.

$$
e^{-\left(\frac{\left(\frac{733-\max \{733 ; 995 ; 673 ; \ldots ; 594\}}{\text { standartsapma }\{733 ; 995 ; 673 ; \ldots ; 594\}}\right)}{2}\right)^{2}}=0,218385
$$

Ardından 13 numaralı denklemden yararlanılır.

$(0,2) *(0,218385)+(0,2) *(0,351128)+(0,2) *$ $(0,970301)+(0,2) *(0,152567)+(0,2) *(0,782485)$ $=0,494973$

10 numaralı denklemden yer alan değeri ölçüt için en iyi durumun maksimizasyon veya minimizasyon olmasına göre farklılaştığından dolayı son ölçüt için çıkarma işlemine gerek kalmamaktadır. Ölçüt 5 için yapılan normalizasyon işlemindeki farklılık aşağıda gösterilmiştir.

$$
e^{-\left(\frac{\left(\frac{640-\min \{640 ; 588 ; 776 ; \ldots ; 561\}}{\text { standartsapma }\{640 ; 588 ; 776 ; \ldots ; 561\}}\right)^{2}}{2}\right)}=0,782485
$$

Açıklanan işlemlerin tüm veri setleri ve alternatiflere uygulanması sonucu elde edilen değerleri Tablo 4'te sunulmuştur. 
Tablo 4: Alternatiflerin Değerleri

\begin{tabular}{|c|c|c|c|c|c|c|c|}
\hline & & 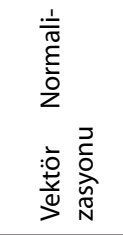 & 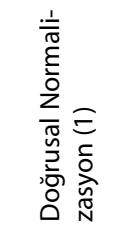 & 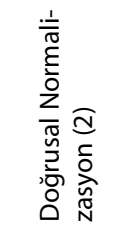 & 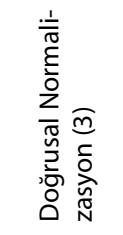 & 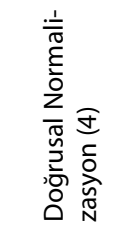 & 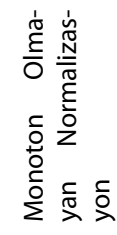 \\
\hline \multirow{10}{*}{ 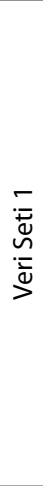 } & Alternatif 1 & 0,187716 & 0,769322 & 0,640348 & 0,561446 & 0,062308 & 0,494973 \\
\hline & Alternatif 2 & 0,191672 & 0,785156 & 0,653163 & 0,620252 & 0,063623 & 0,541560 \\
\hline & Alternatif 3 & 0,114009 & 0,594952 & 0,464050 & 0,223627 & 0,037942 & 0,103041 \\
\hline & Alternatif 4 & 0,223607 & 0,852527 & 0,718177 & 0,675876 & 0,075124 & 0,665262 \\
\hline & Alternatif 5 & 0,212326 & 0,820374 & 0,685680 & 0,530055 & 0,071791 & 0,506253 \\
\hline & Alternatif 6 & 0,175149 & 0,750974 & 0,622528 & 0,630189 & 0,057080 & 0,634682 \\
\hline & Alternatif 7 & 0,139330 & 0,662545 & 0,528238 & 0,369418 & 0,045866 & 0,286977 \\
\hline & Alternatif 8 & 0,203929 & 0,798847 & 0,665988 & 0,504661 & 0,069055 & 0,420038 \\
\hline & Alternatif 9 & 0,126355 & 0,630667 & 0,499820 & 0,348715 & 0,041714 & 0,361032 \\
\hline & Alternatif 10 & 0,224469 & 0,857035 & 0,722341 & 0,726302 & 0,075498 & 0,664893 \\
\hline \multirow{10}{*}{ 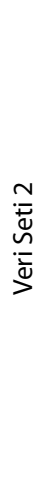 } & Alternatif 1 & 0,197803 & 0,777894 & 0,638743 & 0,539999 & 0,066712 & 0,543275 \\
\hline & Alternatif 2 & 0,122886 & 0,629377 & 0,494216 & 0,419488 & 0,040323 & 0,325274 \\
\hline & Alternatif 3 & 0,175142 & 0,738817 & 0,599667 & 0,578732 & 0,058646 & 0,544909 \\
\hline & Alternatif 4 & 0,118722 & 0,605441 & 0,466362 & 0,244296 & 0,039808 & 0,136788 \\
\hline & Alternatif 5 & 0,169585 & 0,714671 & 0,579998 & 0,468274 & 0,056762 & 0,358709 \\
\hline & Alternatif 6 & 0,224008 & 0,853979 & 0,715232 & 0,787663 & 0,074549 & 0,729997 \\
\hline & Alternatif 7 & 0,221112 & 0,833839 & 0,699205 & 0,688791 & 0,074047 & 0,669970 \\
\hline & Alternatif 8 & 0,236950 & 0,872209 & 0,734565 & 0,768625 & 0,079420 & 0,762979 \\
\hline & Alternatif 9 & 0,154899 & 0,676761 & 0,541964 & 0,370793 & 0,052190 & 0,314184 \\
\hline & Alternatif 10 & 0,172549 & 0,727080 & 0,590940 & 0,500838 & 0,057543 & 0,432791 \\
\hline \multirow{10}{*}{ 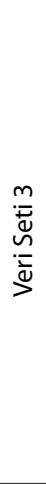 } & Alternatif 1 & 0,138284 & 0,650639 & 0,525085 & 0,432469 & 0,045267 & 0,366593 \\
\hline & Alternatif 2 & 0,209346 & 0,782124 & 0,654108 & 0,507521 & 0,071735 & 0,465126 \\
\hline & Alternatif 3 & 0,159298 & 0,684405 & 0,562621 & 0,462595 & 0,053179 & 0,376754 \\
\hline & Alternatif 4 & 0,157997 & 0,661517 & 0,532287 & 0,247189 & 0,054699 & 0,203855 \\
\hline & Alternatif 5 & 0,155991 & 0,685716 & 0,556486 & 0,468889 & 0,052186 & 0,440943 \\
\hline & Alternatif 6 & 0,128038 & 0,622336 & 0,500791 & 0,369995 & 0,041741 & 0,258747 \\
\hline & Alternatif 7 & 0,226461 & 0,813942 & 0,688977 & 0,570467 & 0,077915 & 0,569829 \\
\hline & Alternatif 8 & 0,262625 & 0,905231 & 0,783273 & 0,809179 & 0,088820 & 0,806255 \\
\hline & Alternatif 9 & 0,168728 & 0,709768 & 0,581291 & 0,478518 & 0,056249 & 0,429541 \\
\hline & Alternatif 10 & 0,174208 & 0,715989 & 0,593418 & 0,478671 & 0,058210 & 0,348985 \\
\hline \multirow{10}{*}{ 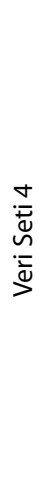 } & Alternatif 1 & 0,169298 & 0,722827 & 0,574789 & 0,576781 & 0,057094 & 0,538759 \\
\hline & Alternatif 2 & 0,196866 & 0,781051 & 0,632466 & 0,652097 & 0,066316 & 0,595743 \\
\hline & Alternatif 3 & 0,245233 & 0,870021 & 0,724949 & 0,678322 & 0,083581 & 0,624527 \\
\hline & Alternatif 4 & 0,178947 & 0,712859 & 0,567415 & 0,367821 & 0,061842 & 0,270877 \\
\hline & Alternatif 5 & 0,124950 & 0,604367 & 0,455783 & 0,196257 & 0,042907 & 0,097620 \\
\hline & Alternatif 6 & 0,146615 & 0,682762 & 0,537850 & 0,542188 & 0,048443 & 0,472670 \\
\hline & Alternatif 7 & 0,205487 & 0,778291 & 0,633311 & 0,545108 & 0,070324 & 0,465941 \\
\hline & Alternatif 8 & 0,121485 & 0,621336 & 0,475212 & 0,427631 & 0,040409 & 0,367017 \\
\hline & Alternatif 9 & 0,172060 & 0,716108 & 0,571229 & 0,464290 & 0,058296 & 0,385969 \\
\hline & Alternatif 10 & 0,209450 & 0,801324 & 0,655704 & 0,591807 & 0,070789 & 0,472190 \\
\hline
\end{tabular}




\begin{tabular}{|c|c|c|c|c|c|c|c|}
\hline \multirow{10}{*}{ 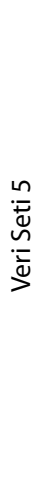 } & Alternatif 1 & 0,091234 & 0,537373 & 0,404992 & 0,146644 & 0,030366 & 0,091852 \\
\hline & Alternatif 2 & 0,204655 & 0,791610 & 0,656400 & 0,634434 & 0,068240 & 0,564542 \\
\hline & Alternatif 3 & 0,217466 & 0,806624 & 0,670653 & 0,577664 & 0,072975 & 0,523045 \\
\hline & Alternatif 4 & 0,185776 & 0,742124 & 0,607518 & 0,531965 & 0,062143 & 0,542697 \\
\hline & Alternatif 5 & 0,174129 & 0,736938 & 0,600967 & 0,589519 & 0,057511 & 0,530088 \\
\hline & Alternatif 6 & 0,189999 & 0,752130 & 0,621806 & 0,532381 & 0,063376 & 0,460844 \\
\hline & Alternatif 7 & 0,153484 & 0,676064 & 0,542949 & 0,424937 & 0,051061 & 0,352736 \\
\hline & Alternatif 8 & 0,209676 & 0,792254 & 0,661346 & 0,577343 & 0,070063 & 0,521016 \\
\hline & Alternatif 9 & 0,190827 & 0,754831 & 0,621715 & 0,553798 & 0,063844 & 0,562169 \\
\hline & Alternatif 10 & 0,180651 & 0,731352 & 0,595533 & 0,429528 & 0,060420 & 0,426387 \\
\hline \multirow{10}{*}{ 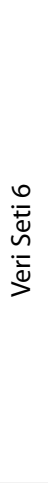 } & Alternatif 1 & 0,198025 & 0,770411 & 0,640985 & 0,593040 & 0,067721 & 0,570156 \\
\hline & Alternatif 2 & 0,236351 & 0,865091 & 0,730770 & 0,731071 & 0,080879 & 0,714427 \\
\hline & Alternatif 3 & 0,210260 & 0,801010 & 0,670079 & 0,579525 & 0,071559 & 0,557552 \\
\hline & Alternatif 4 & 0,169680 & 0,722590 & 0,592649 & 0,526392 & 0,056244 & 0,455000 \\
\hline & Alternatif 5 & 0,210814 & 0,798584 & 0,665945 & 0,601757 & 0,072121 & 0,587112 \\
\hline & Alternatif 6 & 0,168166 & 0,691948 & 0,560898 & 0,327937 & 0,058051 & 0,307294 \\
\hline & Alternatif 7 & 0,173711 & 0,721857 & 0,592114 & 0,498735 & 0,058463 & 0,412512 \\
\hline & Alternatif 8 & 0,130936 & 0,637207 & 0,502886 & 0,383111 & 0,043001 & 0,385198 \\
\hline & Alternatif 9 & 0,164369 & 0,695583 & 0,562281 & 0,373590 & 0,055811 & 0,335646 \\
\hline & Alternatif 10 & 0,107694 & 0,571682 & 0,438899 & 0,284455 & 0,036149 & 0,238756 \\
\hline \multirow{10}{*}{ 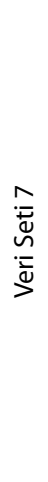 } & Alternatif 1 & 0,176901 & 0,735216 & 0,602415 & 0,476799 & 0,058881 & 0,434659 \\
\hline & Alternatif 2 & 0,181394 & 0,748981 & 0,620937 & 0,532187 & 0,060150 & 0,465609 \\
\hline & Alternatif 3 & 0,186346 & 0,763370 & 0,634021 & 0,565739 & 0,061733 & 0,561335 \\
\hline & Alternatif 4 & 0,158780 & 0,699590 & 0,571792 & 0,466825 & 0,052516 & 0,379278 \\
\hline & Alternatif 5 & 0,156589 & 0,687357 & 0,556464 & 0,379874 & 0,052096 & 0,399175 \\
\hline & Alternatif 6 & 0,260095 & 0,926294 & 0,794385 & 0,839700 & 0,086418 & 0,826238 \\
\hline & Alternatif 7 & 0,153665 & 0,679388 & 0,549659 & 0,380949 & 0,051124 & 0,353553 \\
\hline & Alternatif 8 & 0,175985 & 0,723399 & 0,595633 & 0,431309 & 0,058701 & 0,354802 \\
\hline & Alternatif 9 & 0,201739 & 0,792073 & 0,657923 & 0,569805 & 0,067181 & 0,560760 \\
\hline & Alternatif 10 & 0,154408 & 0,693262 & 0,559112 & 0,402785 & 0,051201 & 0,343317 \\
\hline \multirow{10}{*}{ 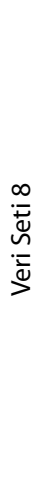 } & Alternatif 1 & 0,161298 & 0,728774 & 0,598877 & 0,434765 & 0,052931 & 0,368420 \\
\hline & Alternatif 2 & 0,183743 & 0,777164 & 0,651194 & 0,524776 & 0,060322 & 0,429275 \\
\hline & Alternatif 3 & 0,192708 & 0,812624 & 0,679857 & 0,665144 & 0,062998 & 0,581456 \\
\hline & Alternatif 4 & 0,197380 & 0,813865 & 0,687612 & 0,571594 & 0,064817 & 0,506350 \\
\hline & Alternatif 5 & 0,229275 & 0,891855 & 0,764743 & 0,761114 & 0,075161 & 0,700599 \\
\hline & Alternatif 6 & 0,152371 & 0,705871 & 0,573104 & 0,393174 & 0,049754 & 0,314895 \\
\hline & Alternatif 7 & 0,188684 & 0,793221 & 0,666754 & 0,559905 & 0,061894 & 0,519045 \\
\hline & Alternatif 8 & 0,179761 & 0,768412 & 0,637979 & 0,385671 & 0,059269 & 0,353800 \\
\hline & Alternatif 9 & 0,165123 & 0,736152 & 0,610192 & 0,597766 & 0,053700 & 0,515646 \\
\hline & Alternatif 10 & 0,179537 & 0,768824 & 0,642708 & 0,487748 & 0,059155 & 0,386028 \\
\hline
\end{tabular}




\begin{tabular}{|c|c|c|c|c|c|c|c|}
\hline \multirow{10}{*}{ 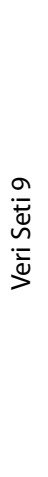 } & Alternatif 1 & 0,166876 & 0,686721 & 0,560811 & 0,391604 & 0,056820 & 0,205805 \\
\hline & Alternatif 2 & 0,092362 & 0,534858 & 0,402882 & 0,142238 & 0,030394 & 0,045208 \\
\hline & Alternatif 3 & 0,203465 & 0,781743 & 0,649767 & 0,643824 & 0,069293 & 0,550317 \\
\hline & Alternatif 4 & 0,096459 & 0,554919 & 0,429205 & 0,318863 & 0,031193 & 0,202421 \\
\hline & Alternatif 5 & 0,187686 & 0,747320 & 0,617754 & 0,576215 & 0,063227 & 0,417629 \\
\hline & Alternatif 6 & 0,228490 & 0,819560 & 0,694602 & 0,630505 & 0,078257 & 0,533119 \\
\hline & Alternatif 7 & 0,194169 & 0,759347 & 0,634341 & 0,617379 & 0,064253 & 0,504432 \\
\hline & Alternatif 8 & 0,176836 & 0,703093 & 0,578106 & 0,404093 & 0,060729 & 0,248154 \\
\hline & Alternatif 9 & 0,177937 & 0,712935 & 0,585440 & 0,436808 & 0,060556 & 0,306584 \\
\hline & Alternatif 10 & 0,247604 & 0,851933 & 0,726280 & 0,623430 & 0,085279 & 0,504669 \\
\hline \multirow{10}{*}{ 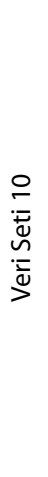 } & Alternatif 1 & 0,226888 & 0,837850 & 0,690390 & 0,552307 & 0,077275 & 0,519821 \\
\hline & Alternatif 2 & 0,130374 & 0,640939 & 0,493480 & 0,400000 & 0,043506 & 0,409588 \\
\hline & Alternatif 3 & 0,177036 & 0,735216 & 0,591261 & 0,518695 & 0,059499 & 0,415724 \\
\hline & Alternatif 4 & 0,208528 & 0,808174 & 0,662088 & 0,615378 & 0,070079 & 0,554709 \\
\hline & Alternatif 5 & 0,223615 & 0,842398 & 0,695529 & 0,697992 & 0,075551 & 0,703217 \\
\hline & Alternatif 6 & 0,164210 & 0,709945 & 0,566047 & 0,495826 & 0,055107 & 0,452833 \\
\hline & Alternatif 7 & 0,151279 & 0,660929 & 0,516529 & 0,274455 & 0,051960 & 0,244228 \\
\hline & Alternatif 8 & 0,165638 & 0,713937 & 0,570421 & 0,555295 & 0,055207 & 0,477804 \\
\hline & Alternatif 9 & 0,157487 & 0,680492 & 0,535900 & 0,381131 & 0,053735 & 0,385941 \\
\hline & Alternatif 10 & 0,172882 & 0,728151 & 0,581820 & 0,557377 & 0,058081 & 0,513063 \\
\hline
\end{tabular}

MOORA yöntemi için tüm normalizasyon yöntemleri kullanılarak elde edilen değerlerinin arasındaki ilişkiyi incelemek amacıyla ikili olarak korelasyon analizleri gerçekleştirilmiştir. Korelasyon analizi gerçekleştirilmeden önce sonuçların parametrik testlere uy- gunluğunu test etmek amacıyla, veri setinin normal dağılıma uygunluğu varsayımı incelenmiştir (Newbold vd., 2003, 551). Bu inceleme için değerler SPSS 18 programına girilmiş ve Tablo 5'teki sonuçlar elde edilmiştir.

Tablo 5: Normal Dağılıma Uygunluk Testi

\begin{tabular}{|l|c|c|c|c|c|c|}
\hline & \multicolumn{3}{|c|}{ Kolmogorov-Smirnov } & \multicolumn{3}{c|}{ Shapiro-Wilk } \\
\cline { 2 - 7 } & Değer & $\begin{array}{c}\text { Serbestlik } \\
\text { derecesi }\end{array}$ & P-değeri & Değer & $\begin{array}{c}\text { Serbestlik } \\
\text { derecesi }\end{array}$ & P-değeri \\
\hline Vektör Normalizasyonu &, 062 & 100 &, $200^{*}$ &, 989 & 100 &, 571 \\
\hline $\begin{array}{l}\text { Doğrusal Normalizasyon } \\
(1)\end{array}$ &, 051 & 100 &, $200^{*}$ &, 992 & 100 &, 809 \\
\hline $\begin{array}{l}\text { Doğrusal Normalizasyon } \\
(2)\end{array}$ &, 057 & 100 &, $200^{*}$ &, 991 & 100 &, 773 \\
\hline $\begin{array}{l}\text { Doğrusal Normalizasyon } \\
\text { (3) }\end{array}$ &, 063 & 100 &, $200^{*}$ &, 989 & 100 &, 550 \\
\hline $\begin{array}{l}\text { Doğrusal Normalizasyon } \\
\text { (4) }\end{array}$ &, 067 & 100 &, $200^{*}$ &, 988 & 100 &, 488 \\
\hline $\begin{array}{l}\text { Monoton Olmayan } \\
\text { Normalizasyon }\end{array}$ &, 065 & 100 &, $200^{*}$ &, 989 & 100 &, 553 \\
\hline
\end{tabular}

( Not: *Normal dağılıma uygunluk hipotezinin reddedilmediği durumlar)

Hem Kolmogorov-Smirnov testine göre hem de Shapiro-Wilk testine göre değerleri normal dağılıma uygunluk testini geçtiğinden, parametrik korelasyon analizi (Pearson), korelasyon hesaplamaları için uygundur. Korelasyon değerlerinin hesaplanması için
SPSS 18 programında Pearson Korelasyon işlemi seçilerek Tablo 6'daki sonuçlara ulaşıımıştır

Tablo 6'da satır ile sütunun kesişiminde yer alan değer ilgili hücrenin bulunduğu satır ve sütundaki normalizasyon yöntemlerinin değişkenleri temsil etti- 
ği korelasyon işleminin sonucunu vermektedir. Örnek vermek gerekirse, vektörel normalizasyon satırı ile doğrusal normalizasyon (3) sütunu kesişimindeki $\% 86,4$ değeri vektörel normalizasyon değişkeni ile doğrusal normalizasyon (3) değişkenlerini içeren korelasyon analizinin sonucudur.

Tablo 6: Normalizasyon Yöntemlerine göre Sonuçlar Arasındaki Korelasyon Değerleri

\begin{tabular}{|c|c|c|c|c|c|}
\hline & 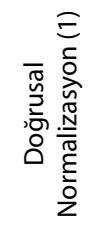 & 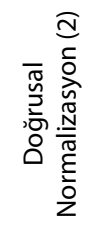 & 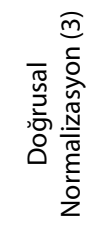 & 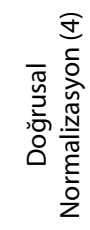 & 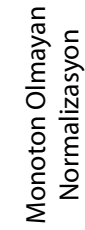 \\
\hline $\begin{array}{c}\text { Vektörel } \\
\text { Normalizasyon }\end{array}$ & 0,980 & 0,976 & 0,864 & 0,998 & 0,841 \\
\hline $\begin{array}{c}\text { Doğrusal } \\
\text { Normalizasyon (1) }\end{array}$ & & 0,996 & 0,905 & 0,966 & 0,884 \\
\hline $\begin{array}{c}\text { Doğrusal } \\
\text { Normalizasyon (2) }\end{array}$ & & & 0,900 & 0,961 & 0,874 \\
\hline $\begin{array}{c}\text { Doğrusal } \\
\text { Normalizasyon (3) }\end{array}$ & & & & 0,841 & 0,964 \\
\hline $\begin{array}{c}\text { Doğrusal } \\
\text { Normalizasyon (4) }\end{array}$ & & & & & 0,818 \\
\hline
\end{tabular}

Korelasyon katsayısı sonuçlar arasındaki ilişkinin gücünü göstermektedir. $\% 0-\% 25$ arası korelasyon değeri ilişkinin çok zayıf olduğunu, \%26-\%49 arası korelasyon değeri ilişkinin zayıf olduğunu, \%50-\%69 arası korelasyon değeri ilişkinin orta seviyede olduğunu, \%70-\%89 arası korelasyon değeri ilişkinin yüksek olduğunu, \%90-\%100 arası korelasyon değeri ise ilişkinin çok yüksek olduğunu ifade etmektedir (Kalaycı, 2010; 116). Vektörel normalizasyon sonuçları incelendiğinde doğrusal normalizasyon (4) olarak adlandırılan yöntem ile elde edilen sonuçlar arası ilişki \%99,8 olarak görülmektedir. Bu değer, iki yöntemden elde edilen sonuçların neredeyse aynı olduğunu ifade etmektedir. Yine doğrusal normalizasyon (1) sonuçları ve doğrusal normalizasyon (2) olarak adlandırılan yöntem ile elde edilen sonuçlar arası ilişki de \%99,6 bulunmuştur ki bu da sonuçların hemen hemen aynı olduğunu göstermektedir. Bu da sonuçların neredeyse birbirine eşit olduğunu göstermektedir. Tablo 6'daki değerler incelendiğinde, monoton olmayan normalizasyon ve doğrusal normalizasyon (3) olarak adlandırılan yöntemlerin diğer normalizasyon yöntemleri ile ilişkisi orta düzeyde kalmakta ve farklı alternatiflerin tercih edilmesi sonucunu doğurabilmektedir. Bu iki yöntemin kendi aralarındaki ilişki düzeyi ise \%96,4 ile oldukça yüksektir. Bu ilişki katsayılarına göre normalizasyon yöntemlerini iki ana kategoride toplamak mümkün görünmektedir. Çok sayıda değerlendirme ölçütünü birarada inceleyip alternatifler arasında doğru seçim yapabilmek amacıyla normalizasyon yöntemlerinden elde edilen değerler arasındaki korelasyon değerlerinin mümkün olduğunca \%100 değerine yaklaşması gerektiğinden \%95 korelasyon değeri bir sınır olarak düşünülmüş ve iki farklı kategori oluşturulmuştur. Buna göre ilk kategoride yer alan normalizasyon yöntemlerinden herhangi birinin Moora hesaplamalarında kullanımında sakınca yokken, ikinci kategoride yer alan normalizasyon yöntemlerinin kullanımı önerilmemektedir.

Normalizasyon Yöntemleri 1. Kategori (Korelasyon değerleri \%95 ve üstü)

- Vektörel Normalizasyon

- Doğrusal Normalizasyon (1)

- Doğrusal Normalizasyon (2)

- Doğrusal Normalizasyon (4)

Normalizasyon Yöntemleri 2. Kategori (Korelasyon değerleri \%95'in altında)

- Doğrusal Normalizasyon (3)

- Monoton Olmayan Normalizasyon

\section{SONUÇ VE ÖNERILER}

Bu çalışma kapsamında ilk olarak normalizasyon yöntemlerine değinilmiş ve çok ölçütlü karar verme yöntemlerinde hangi normalizasyon yöntemlerinin tercih edildiğine dair bir inceleme yapılmıştır. Ardından üzerinde uygulanan normalizasyon yöntemi açısından fikir birliği bulunmayan çok ölçütlü karar verme yöntemlerinden biri olan Moora yönteminin işleyişi açıklanmış ve MS Excel programındaki fonksiyonlardan yararlanarak oluşturulan on alternatif ve beş değerlendirme ölçütüne göre on farklı veri seti için tüm normalizayon yöntemlerinin kullanımı ile Moora sonuçları belirlenmiştir. Tablo 4'te yer alan tercih sıraları incelendiğinde özellikle vektör normalizasyonu, doğrusal normalizasyon (1), doğrusal normalizasyon (2) ve doğrusal normalizasyon (4) ile elde edilen sonuçların hemen hemen aynı olduğu görülmektedir. Özellikle monoton olmayan normalizasyonda elde edilen sonuçlardaki farklılıklar daha belirgindir. Tablo 1'de sunulan literatür bilgisi de hatırlanacak olursa monoton olmayan normalizasyon yöntemi kullanılmış bir çok ölçütlü karar verme yöntemi çalışması da bulunamamıştır. Normalizasyon yöntemlerinin açıklandığı bazı çalışmalarda da bu konuya vurgu yapılmakta ve literatürde monoton olmayan normalizasyon yönteminin nadiren kullanıldığı ifade edilmektedir (Shih vd., 2007: 805). Bu noktada dikkat edilmesi gereken diğer bir nokta doğrusal normalizasyon (1), 
doğrusal normalizasyon (2), doğrusal normalizasyon (3) ve monoton olmayan normalizasyon yöntemlerinin işleyişinde değerin münkün olduğunca küçük olmasının istendiği değerlendirme ölçütleri için yapılan normalizasyon işlemi en iyi sonuca yakınlığı gösteren performans değerlerini verdiğinden Moora yönteminin işleyişinde gösterilen Eşitlik 12 ve Eşitlik 13 işlemlerindeki faydası ölçütler için yapılan çıkarma işlemine gerek kalmamaktadır. Vektör normalizasyonu ve doğrusal normalizasyon (4) yöntemlerinde ise orjinal işleyişe uyulması gerekmektedir. Buna göre Moora yönteminin adımları aşağıdaki gibi düzenlenebilir.

Durum 1: Vektör Normalizasyonu veya Doğrusal Normalizasyon (4) kullanılıyor ise;

Adım 1: Eşitlik 11'de gösterilen karar matrisinin oluşturulması

Adım 2: Vektör normalizasyonu yapılacaksa Eşitlik 2, Doğrusal Normalizasyon 4 yapılacaksa Eşitlik 9 kullanılarak Normalizasyon işlemlerinin yapılması

Adım 3: Ölçüt ağırlıkları birbirine eşit ise Eşitlik 12, ölçüt ağırlıkları birbirinden farklı ise Eşitlik 13 kullanılarak her bir alternatif için tek bir değerin bulunması

Durum 2: Doğrusal normalizasyon (1), doğrusal normalizasyon (2), doğrusal normalizasyon (3) veya monoton olmayan normalizasyon yöntemlerinden biri kullanılıyor ise;

Adım 1: Eşitlik 11'de gösterilen karar matrisinin oluşturulması

Adım 2: Doğrusal Normalizasyon (1) yapılacaksa Eşitlik 3 ve Eşitlik 4, Doğrusal Normalizasyon (2) yapılacaksa Eşitlik 5 ve Eşitlik 6, Doğrusal Normalizasyon (3) yapılacaksa Eşitlik 7 ve Eşitlik 8, monoton olmayan normalizasyon yapılacaksa Eşitlik 10 kullanılarak Normalizasyon işlemlerinin yapılması

Adım 3: Ölçüt ağırlıkları birbirine eşit ise aşağıda belirtilen Eşitlik 14, ölçüt ağırlıkları birbirinden farklı ise aşağıda sunulan Eşitlik 15 kullanılarak her bir alternatif için tek bir değerin bulunması

$$
\mathrm{y}_{\mathrm{i}}=\sum_{\mathrm{j}=1}^{\mathrm{n}} \mathrm{x}_{\mathrm{ij}}^{*}
$$

Eşitlik 14.

j. = enbüyüklenmesi veya en küçüklenmesi farketmeksizin nitelik ya da ölçüt

$$
\mathrm{y}_{\mathrm{i}}=\sum_{\mathrm{j}=1}^{\mathrm{g}} \mathrm{w}_{\mathrm{j}} \mathrm{x}_{\mathrm{ij}}^{*}(\mathrm{j}=1,2, \ldots, \mathrm{n})
$$

Eşitlik 15.
$W_{\mathrm{j}}=\mathrm{j}$. Nitelik ya da ölçütün ağırlık (önem) katsayısı

Durum 2' de sunulan adımlar tamamlandığında elde edilen $y_{i}$ değeri karar matrisindeki enbüyüklerin (faydalı nitelik ya da ölçütler) ve enküçüklerin (faydasız nitelik ya da ölçütler) toplamlarına bağlı olarak sadece pozitif değer alacak negatif olmayacaktır. $y_{i}$ değerlerinin sıralaması nihai öncelikleri gösterir. En iyi alternatif en yüksek $y_{i}$ değerine sahip olan iken, en kötü alternatif en düşük $y_{i}$ değerine sahip olan alternatiftir.

Bu çalışma kapsamında normalizasyon yöntemlerinin çok ölçütlü karar verme yönteminden elde edilen sonuçlara nasıl bir etkide bulunduğunu görmek amacıyla 10 alternatif ve 5 değerlendirme ölçütü içeren 10 farklı veri seti oluşturulmuş ve bu veri setlerine tüm normalizasyon yöntemleri birer birer denenerek sonuçlar korelasyon analizine tabi tutulmuştur. Veri setlerinin gerçek işletme problemlerini daha iyi yansıtabilmesini sağlamak amacıyla veri seti türetilirken farklı sayı aralıklarında ölçekler oluşturulmuş ve olası değişik senaryoları inceleyebilmek için de değerlendirme ölçütlerinden biri açısından en küçük değerin en iyi durumu gösterdiği göz önüne alınarak hesaplamalar gerçekleştirilmiştir. Elde edilen sonuçlar korelasyon analizine tabi tutulduğunda yöntemlerin iki ana kategoride toplandığı görülmektedir. Birinci kategori olarak ifade edilebilecek olan Vektörel Normalizasyon, Doğrusal Normalizasyon (1), Doğrusal Normalizasyon (2) ve Doğrusal Normalizasyon (4) yöntemlerinin ikili korelasyon değerlerinin hepsi \%95 değerinin üzerindedir. İkinci kategoride kalan Doğrusal Normalizasyon (3) ve Monoton Olmayan Normalizasyon yöntemleri ise Moora yönteminin orijinal yapısında uygulandığı literatür araştırması sonucunda ortaya çıkan vektörel normalizasyon ve doğrusal normalizasyon (4) yöntemleri ile karşılaştırıldığında korelasyon değeri düşük kalmaktadır. Bu nedenle ikinci kategori olarak ifade edilen Doğrusal Normalizasyon (3) ve Monoton Olmayan Normalizasyon yöntemlerinin Moora yöntemi için kullanımı önerilmemektedir. illk kategoride yer alan, Vektörel Normalizasyon, Doğrusal Normalizasyon (1), Doğrusal Normalizasyon (2) ve Doğrusal Normalizasyon (4) yöntemlerinin herhangi biri Moora yöntemi ile karar verme sürecinde rahatlıkla kullanılabilir. 


\section{KAYNAKLAR}

Aalami, H.A., Moghaddam, M.P. ve Yousefi, G.R. (2010) "Modeling and Prioritizing Demand Response Programs in Power Markets" Electric Power Systems Research, 80: 426-435.

Ayala, J.G. (2012) "Selecting Irrigation Water Pricing Alternatives Using A Multi-Methodological Approach" Mathematical and Computer Modelling, 55: 861-883.

Balezentis, A. Balezentis, T. ve Brauers, W.K.M. (2012) "Personnel Selection Based on Computing with Words and Fuzzy MULTIMOORA" Expert Systems with Applications, 39: 7961-7967.

Brauers, W.K.M. ve Zavadskas, E.K. (2009) "Robustness of The Multi-Objective MOORA Method with A Test for The Facilities Sector" Technological and Economic Development of Economy: Baltic J on Sustainability, 15: 352-375.

Chakraborty, S. (2011) "Applications of The MOORA Method for Decision Making in Manufacturing Environment" Int J Adv Manuf Technol, 54: 1155-1166.

Chatterjee, P., Athawale, V.M. ve Chakraborty, S. (2011) "Materials Selection Using Complex Proportional Assessment and Evaluation of Mixed Data Methods" Materials and Design, 32: 851-860.

Chatterjee, P. ve Chakraborty, S. (2012) "Material Selection Using Preferential Ranking Methods" Materials and Design, 35: 384-393.

Dai, L. ve Wang, J. (2011) "Evaluation of The Profitability of Power Listed Companies Based on Entropy Improved TOPSIS Method" Procedia Engineering, 15: $4728-4732$.

Das, M.C., Sarkar, B. ve Ray, S. (2012) "A Framework To Measure Relative Performance of Indian Technical Institutions Using Integrated Fuzzy AHP and COPRAS Methodology" Socio-Economic Planning Sciences, 1-12. (Baskıda makale).

Huang, W. ve Huang, Y.Y. (2012) "Research on The Performance Evaluation of Chongqing Electric Power Supply Bureaus Based on TOPSIS" Energy Procedia, 14: $899-905$.

Kaklauskas, A., Zavadskas, E.K., Naimaviciene, J., Krutinis, M., Plakys, V. ve Venskus, D. (2010) "Model for A Complex Analysis of Intelligent Built Environment" Automation in Construction, 19: 326-340.

Kaklauskas, A., Zavadskas, E.K. ve Trinkunas, V. (2007) "A Multiple Criteria Decision Support On-Line System for Construction" Engineering Applications of Artificial Intelligence, 20:163-175.
Kalaycı, Ş. (2010) SPSS Uygulamalı Çok Değişkenli İstatistik Teknikleri, Ankara, Asil Yayın Dağıtım.

Karande, P. ve Chakraborty, S. (2012) "Application of Multi-Objective Optimization on The Basis of Ratio Analysis (MOORA) Method for Materials Selection" Materials and Design, 37: 317-324

Kiran, C.P., Clement, S. ve Agrawal, V.P. (2011) "Coding, Evaluation and Optimal Selection of A Mechatronic System" Expert Systems with Applications, 38: 9704-9712.

Lozano-Minguez, E., Kolios, A.J. ve Brennan, F.P. (2011) "Multi-Criteria Assessment of Offshore Wind Turbine Support Structures" Renewable Energy, 36: 28312837.

Mela, K., Tiainen, T. ve Heinisuo, M. (2012) "Comparative Study of Multiple Criteria Decision Making Methods for Building Design" Advanced Engineering Informatics, (baskıda makale)

Newbold, P., Carlson, W.L. ve Thorne, B. (2003) Statistics For Business And Economics, New Jersey, Prentice Hall Inc.

Ouattara, A., Pibouleau, L., Azzaro-Pantel, C., Domenech, S., Baudet, P. ve Yao, B. (2012) "Economic and Environmental Strategies for Process Design” Computers and Chemical Engineering, 36: 174- 188.

Peng, Y., Zhang, Y., Tang, Y. ve Li, S. (2011) "An Incident Information Management Framework Based on Data Integration, Data Mining, and Multi-Criteria Decision Making" Decision Support Systems, 51: 316-327.

Sadeghzadeh, K. ve Salehi, M.B. (2011) "Mathematical Analysis of Fuel Cell Strategic Technologies Development Solutions in The Automotive Industry by The TOPSIS Multi-Criteria Decision Making Method" International Journal of Hydrogen Energy, 36: 13272-13280.

Shih, H-S., Shyur, H-J. ve Lee, E.S. (2007) "An Extension of TOPSIS for Group Decision Making" Mathematical and Computer Modelling, 45: 801-813.

Streimikiene, D., Balezentis, T., Krisciukaitien, I. ve Balezentis, A. (2012) "Prioritizing Sustainable Electricity Production Technologies: MCDM Approach" Renewable and Sustainable Energy Reviews, 16: 3302-3311.

Sun, Y.F., Liang, Z-S., Shan, C.J., Viernstein, H. ve Unger, F. (2011) "Comprehensive Evaluation of Natural Antioxidants and Antioxidant Potentials in Ziziphus Jujuba Mill. Var. Spinosa (Bunge) Hu Ex H. F. Chou Fruits Based on Geographical Origin by TOPSIS Method" Food Chemistry, 124: 1612-1619. 